\title{
Microbial inoculants for the biocontrol of Fusarium spp. in durum wheat
}

\author{
Loredana Baffoni ${ }^{1}$, Francesca Gaggia', Nereida Dalanaj ${ }^{2}$, Antonio Prodi ${ }^{1}$, Paola Nipoti ${ }^{1}$, Annamaria Pisi ${ }^{1}$,
} Bruno Biavati ${ }^{3}$ and Diana Di Gioia ${ }^{1^{*}}$

\begin{abstract}
Background: Fusarium head blight (FHB) is a severe disease caused by different Fusarium species, which affects a wide range of cereal crops, including wheat. It determines from 10 to $30 \%$ of yield loss in Europe. Chemical fungicides are mainly used to reduce the incidence of $\mathrm{FHB}$, but low environmental impact solutions are looked forward. Applications of soil/rhizobacteria as biocontrol agents against FHB in wheat are described in literature, whereas the potential use of lactobacilli in agriculture has scarcely been explored.
\end{abstract}

Results: The aim of this work was to study the inhibitory effect of two bacterial strains, Lactobacillus plantarum SLG17 and Bacillus amyloliquefaciens FLN13, against Fusarium spp. in vitro and to assess their efficacy in field, coupled to the study of the microbial community profile of wheat seeds. Antimicrobial assays were performed on agar plates and showed that the two antagonistic strains possessed antimicrobial activity against Fusarium spp. In the field study, a mixture of the two strains was applied to durum wheat i) weekly from heading until anthesis and ii) at flowering, compared to untreated and fungicide treated plots. The FHB index, combining both disease incidence and disease severity, was used to evaluate the extent of the disease on wheat. A mixture of the two microorganisms, when applied in field from heading until anthesis, was capable of reducing the FHB index. Microbial community profile of seeds was studied via PCR-DGGE, showing the presence of L. plantarum SLG17 in wheat seeds and thus underlining an endophytic behavior of the strain.

Conclusions: L. plantarum SLG17 and B. amyloliquefaciens FLN13, applied as biocontrol agents starting from the heading period until anthesis of wheat plants, are promising agents for the reduction of FHB index.

Keywords: Biocontrol, Lattobacilli, Endophytes, Fusarium head blight

\section{Background}

Fusarium head blight (FHB) is a severe disease diffused worldwide affecting a wide range of cereal crops such as wheat (Triticum L.) and barley (Hordeum L.). Only in Europe the loss due to FHB in wheat harvest is estimated from 10 to 30 \% [1]. The causal agents are mainly Fusarium graminearum Schwabe [teleomorph, Gibberella zeae (Schwabe) Petch] and Fusarium culmorum (WG Smith) Sacc. [2]. These Fusarium species are known to produce several mycotoxins, which can accumulate in the grains and are toxic to both animals and humans [1]. FHB epidemics in nature can strike suddenly, but its severity can vary depending on climate conditions, being favored by

\footnotetext{
* Correspondence: diana.digioia@unibo.it

${ }^{1}$ Department of Agricultural Sciences, University of Bologna, Viale Fanin 44, 40127 Bologna, Italy

Full list of author information is available at the end of the article
}

high humidity and rainfall during flowering [3]. Several authors reported different control measures for FHB [4-6], that include the use of agronomic control techniques, wheat genetic resistance and the use of chemical or biological antagonists. The limited time in which the heads are susceptible to FHB infection (during anthesis and for a short period afterwards) makes this disease a potential target for biological control.

The use of microorganisms against plant pathogens has increased in recent years due to consumers' demand of a reduced chemical products use for the benefits of human health and the environment [7]. Some successful applications of soil/rhizobacteria as biocontrol agents against FHB, with a reduction of Fusarium incidence and mycotoxin level, have already been reported in in vitro assays, greenhouse experiments and field trials [6, 8-10]. These bacteria can also colonize root surface 
and enter root tissues, thus becoming endophytic. Endophytes are of special interest in the field of biocontrol, as they are harmless to plants and are able to inhabit specific ecological niches [11]. From the internal tissues, they can be a source of secondary metabolites acting as elicitors of plant defenses or as antimicrobial agents with potential use to control disease [12]. Typical examples of these molecules are cyclic lipopeptides (LPs) mainly synthesized by species of Bacillus and Pseudomonas [13]. Nevertheless the array of secondary metabolites produced by endophytic bacteria remains to be discovered [14].

In addition to these strains, Lactobacillus spp. members can be interesting as potential biocontrol agents. They are well known as probiotics and protective microorganisms in food and feed against spoilage bacteria or fungi [15]. However, in the agricultural field, their potential use is still sparse, although they can be found inside plant tissues $[16,17]$ and produce bioactive compounds (organic acids, bacteriocins, phenyllactic acid, cyclic dipeptides, fatty acids) with antimicrobial properties against a broad spectrum of phytopathogenic fungi. In particular, different molecules are active against Fusarium [18-20] and some Lactobacillus strains have been found to be capable of mycotoxin detoxification [21, 22].

In this work, the inhibitory effect of Lactobacillus plantarum SLG17 and Bacillus amyloliquefaciens FNL13 was evaluated against strains of F. culmorum and F. graminearum isolated from wheat, and the presence of genes responsible for antimicrobial peptide production was checked. Furthermore, the antagonistic efficacy in controlling FHB was studied in field conditions. PCR-DGGE analyses on wheat seeds were performed to investigate: a) the microbial community profile of wheat grains upon different treatments; b) the endophytic colonization feature of the microbial inoculants; c) Fusarium population in wheat.

\section{Results}

Antimicrobial activity against Fusarium spp

In vitro tests performed on agar plates showed that the two strains used in this work, L. plantarum SLG17 and B. amyloliquefaciens FLN13, possessed antimicrobial activity against all the five Fusarium strains isolated from diseased wheat (Table 1). Both antagonistic strains did not display reciprocal inhibition (data not shown). Antimicrobial activity of $B$. amyloliquefaciens FNL13 against F. culmorum Fc1 was also examined using scanning electron microscopy (SEM) since hyphae adjacent to the inhibition area in the plate tests revealed an unusual brown color. The adherence of B. amyloliquefaciens FNL13 cells on the hyphal surface of $F$. culmorum Fc1 is evident, and the contact zone showed shrinkage with loss of turgidness of hyphae (Fig. 1b) compared to the control grown hyphae (Fig. 1a). Conidia were also subjected to surface alteration (Fig. 1c). In addition, as shown in Fig. 1d, bacterial aggregates close to hyphae embedded in an extracellular matrix could be observed (Fig. 1c).

\section{Detection of genes for plantaricin and LPs synthesis}

L. plantarum SLG17 was positive for $p \ln \mathrm{E} / \mathrm{F}, p \ln \mathrm{K}, p \ln \mathrm{G}$, $p \ln \mathrm{N}$ genes, whereas the $p \ln \mathrm{J}$ gene was not detected (data not shown). The PCR assay using degenerated primers followed by cloning and sequencing of the amplified bands allowed the detection of the genes related to the biosynthesis of surfactin, fengycin and mycosubtilin in the genome of B. amyloliquefaciens FLN13 (Table 2). On the other hand, the $i t u C$ fragment, involved in iturin A production, was not detected.

\section{In field trial and FHB assessment in wheat}

The isolation of FHB agents in the wheat grains resulted positive (75\% of kernel were positive to Fusarium spp. in the Ctr), confirming natural infection of the field.

DI was not significantly different among the four treatments at GS 73, whereas a few differences were observed in DS, with the highest values present in Ctr and Bio-2 $(9.2 \%$ and $11.5 \%)$ and the lowest in Chem (3.3\%). Regarding the FHB index, the lowest value was obtained in Chem (1.6), being statistically different from all the other treatments (Table 3 ).

In the evaluation made at GS 87 , the highest DI, DS and FHB index were observed in Ctr (51.4 \%, $17.5 \%$ and 9.1) and Bio-2 (54 \%, 17.4 \% and 9.0) and no significant differences were observed between them. On the other hand, a significant FHB index reduction was obtained in Bio-1 (49.5 \% reduction) and Chem (82.4\% reduction) compared to Ctr; in both Bio-1 and Chem the DI is statistically different with respect to Ctr (36\% and $30.5 \%$ vs $51.4 \%$ ), whereas DS showed a significant reduction only in Chem (5.5\% vs $17.5 \%)$. The kernel weight was significantly increased $(P \leq 0.05)$ only in Chem (average

Table 1 Source of isolation, species identity and fungal inhibition spectra of L. plantarum SLG17 and B. amyloliquefaciens FLN13; values are expressed as mean \pm SD

\begin{tabular}{lllllll}
\hline \multirow{2}{*}{ Isolates } & \multicolumn{5}{l}{ Antifungal activity: inhibition radius $(\mathrm{mm})$} & \\
\cline { 2 - 7 } & F. culmorum Fc1 & F. culmorum Fc2 & F. culmorum Fc3 & F. graminearum Fg1 & F. graminearum Fg2 & Source \\
\hline L. plantarum SLG17 & $13.67 \pm 0.58$ & $12.67 \pm 2.08$ & $17.33 \pm 2.31$ & $15.67 \pm 1.15$ & $16.33 \pm 3.21$ & Silage \\
B amyloliquefaciens FLN13 & $10.87 \pm 0.06$ & $10.80 \pm 0.10$ & $10.67 \pm 0.21$ & $10.43 \pm 0.06$ & $10.67 \pm 0.06$ & Forest soil \\
\hline
\end{tabular}




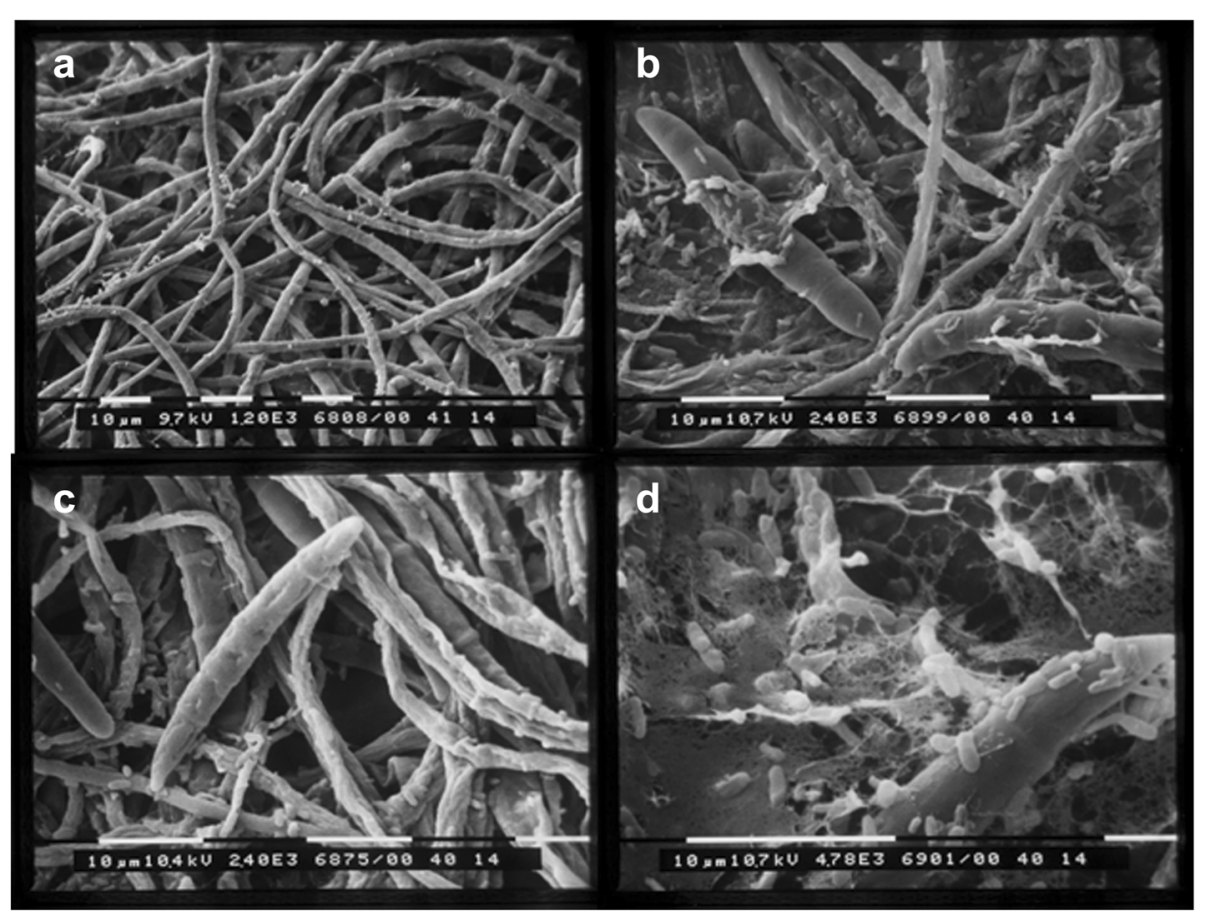

Fig. 1 SEM analysis of antagonistic B. amyloliquefaciens FLN13 interacting with hyphae of F. culmorum FC1 on PDA medium at 5th day after incubation. a normal hyphae of F. culmorum Fc1; b, c damaged hyphae and macroconidia of F. culmorum Fc1; d damaged hyphae with cells of B. amyloliquefaciens FLN13 embedded in a extracellular matrix

weight: $2814 \pm 99 \mathrm{~g}$ ); on the other hand, the observed increase in BIO-1 was not significant compared to Ctr $(2518 \pm 99 \mathrm{~g}$ vs $2455 \pm 102 \mathrm{~g})$. Bio-2 had a kernel weight lower than Ctr $(2410 \pm 79)$ (Table 3).

\section{PCR-DGGE analysis}

Wheat seed bacterial community was firstly investigated in all treatment condition by PCR-DGGE analysis of $16 \mathrm{~S}$ rRNA gene fragments targeting total eubacteria. Profiles of the bacterial communities and UPGMA dendrogram are shown in Fig. 2a and b. The cluster analysis showed a distinct division between Bio-2 and the group Ctr, Chem and Bio-1 (similarity less than $27 \%$ ), and a further division distinguishes $\mathrm{Ctr}$ from Chem and Bio-1 profiles.

Sequencing of selected bands evidenced the presence of five different bacterial species (Table 4). Band 1, detected in Chem and Bio-1, showed $100 \%$ similarity to
Lysobacter soli, while bands 2, 3, and 12 (detected in all profiles, except for band 12 which is present only in Ctr and Bio-1) had $100 \%$ similarity to Pantoea agglomerans. Bands 4, 5 and 7 showed $100 \%$ identity with Erwinia rhapontici; bands 6, 9 (detected in all profiles) and 8 (Bio-2) were identified as Rahnella acquatilis (100\% identity). DGGE fingerprints targeting lactobacilli were rather simple, with a few well-defined bands (Fig. 3a), not detectable in all samples. Bands 1, 2, 3, 4 were particularly visible in the Ctr profile while their intensity decreased in the profiles Bio-1 and Bio-2. These bands and band 5 (Bio-1) had $100 \%$ identity with Exiguobacterium sibiricum (Table 4). Bands 7 and 8 were detected only in Bio-1 and Bio- 2 profile, and had the same migration distance of bands 6 and 9, which represent L. plantarum in the ladder profile. These four bands were also excised and sequenced, showing $100 \%$ similarity with $L$. plantarum

Table 2 Blast results of the sequenced products obtained from PCR amplification using gene-specific degenerated primers from biosynthetic genes of Mycosubtilin synthase, Fengycin synthetase and Surfactin synthase in B. amyloliquefaciens FLN13

\begin{tabular}{lllllll}
\hline $\begin{array}{l}\text { Accession Number } \\
\text { (GenBank) }\end{array}$ & Primer name & Size (bp) & $\begin{array}{l}\text { GeneBank accession } \\
\text { number }\end{array}$ & Identity (\%) & E value & UniProt Accession number \\
\hline KP944004 & Am1-F/Tm1-R & 405 & HG328254.1 & $99 \%$ & 0.0 & $\begin{array}{l}\text { BmyB protein, Mycosubtilin synthase subunit } \\
\text { B (S6Fl96) }\end{array}$ \\
KP944005 & Af2-F/Tf1-R & 441 & HF563562.1 & $99 \%$ & 0.0 & $\begin{array}{l}\text { FenD protein, Fengycin synthetase (M1XBL6) } \\
\text { KP944006 }\end{array}$ \\
\hline As1-F/Ts2-R & 420 & CP003838.1 & $98 \%$ & 0.0 & $\begin{array}{l}\text { SrfAB protein, Surfactin synthase subunit 2 } \\
\text { (LOBHY7) }\end{array}$ \\
\hline
\end{tabular}


Table 3 Mean values of FHB incidence (DI), disease severity (DS) and FHB index at Zadoks growth stage GS 73 and GS 87 in the different treatments (Ctr, Chem, Bio-1, Bio-2)

\begin{tabular}{|c|c|c|c|c|c|c|}
\hline \multirow[t]{2}{*}{ Treatment* } & \multicolumn{3}{|l|}{ GS 73} & \multicolumn{3}{|l|}{ GS 87} \\
\hline & $\overline{D I}(\%)$ & DS (\%) & FHB index & $\overline{D I}(\%)$ & DS (\%) & FHB index \\
\hline Ctr & $30.0^{\mathrm{a}}$ & $9.2^{\mathrm{ab}}$ & $2.8^{\mathrm{b}}$ & $51.4^{b}$ & $17.5^{\mathrm{b}}$ & $9.1^{c}$ \\
\hline Chem & $18.0^{\mathrm{a}}$ & $3.3^{\mathrm{a}}$ & $0.5^{\mathrm{a}}$ & $30.5^{\mathrm{a}}$ & $5.5^{\mathrm{a}}$ & $1.6^{\mathrm{a}}$ \\
\hline Bio-1 & $23.0^{\mathrm{a}}$ & $7.2^{a b}$ & $1.6^{\mathrm{b}}$ & $36.0^{\mathrm{a}}$ & $13.0^{\mathrm{ab}}$ & $4.6^{\mathrm{ab}}$ \\
\hline Bio-2 & $29.0^{\mathrm{a}}$ & $11.5^{\mathrm{b}}$ & $3.5^{\mathrm{b}}$ & $54.0^{\mathrm{b}}$ & $17.4^{\mathrm{b}}$ & $9.0^{b c}$ \\
\hline
\end{tabular}

*Within columns, means followed by different letters differ significantly (Tukey's test, $P \leq 0.05$ )

(Table 5). Unexpectedly, primers targeting lactobacilli allowed the amplification of B. amyloliquefaciens FLN13, which was thus present in this DGGE profile. An in silico evaluation of Lac1 and Lac2 primer sequences on $16 \mathrm{~S}$ rDNA of Bacillus spp. evidenced a possible amplification of the ribosomal DNA.

The DGGE fingerprints of the Fusarium community were also simple and not many differences were detected among plots treated with microorganisms and the control plots (Fig. 3b). A lower band intensity was shown in
Bio-1 profile. Mainly, bands excised (1, 2, 3 and 4) had $100 \%$ similarity to F. culmorum (Table 6) and were detected in all profiles. Bands 7 and 8, whose detection was weak in Bio-1, had sequence homology with $F$. graminearum.

\section{Discussion}

The use of microorganisms for pathogen control in plants is largely studied and applied to several crops of economic value, with consequent reduction of the spread of chemical agents in the environment. Bacillus spp. are the most commercially successful biocontrol agents, with more than 10 Bacillus-based registered formulations [23], whereas Lactobacillus spp. strains, although included in multi-strain bio-fertilizers [17], have rarely been used for biocontrol intervention strategy [24]. In this work, two bacterial strains, B. amyloliquefaciens FLN13 and L. plantarum SLG17, previously selected for their strong inhibitory activity against several plant pathogenic fungi, were checked for their in vitro antifungal activity against strains of F. culmorum and F. graminearum and, as a mixture,

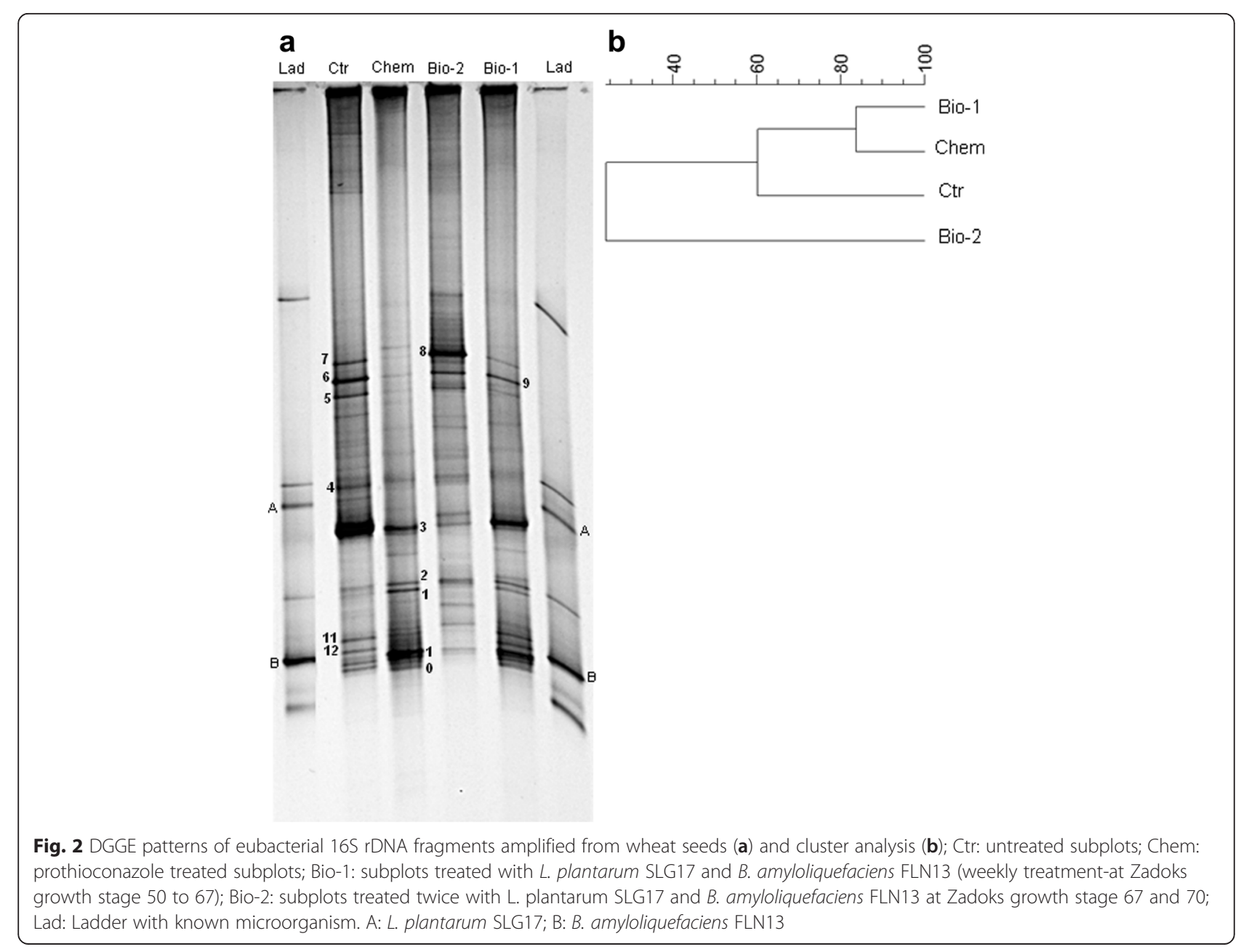


Table 4 Eubacteria sequence alignment with blast

\begin{tabular}{|c|c|c|c|}
\hline Band & Closest match & $\%$ similarity $^{\mathrm{a}}$ & $\begin{array}{l}\text { Accession number } \\
\text { (GenBank) }\end{array}$ \\
\hline 1 & $\begin{array}{l}\text { Lysobacter soli - L. } \\
\text { enzymogenes }\end{array}$ & $100 \%$ & KP943989 \\
\hline 2 & Pantoea agglomerans & $100 \%$ & KP943990 \\
\hline 3 & nd & - & - \\
\hline 4 & Erwinia rhapontici strain & $100 \%$ & KP943991 \\
\hline 5 & Erwinia rhapontici strain & $100 \%$ & KP943992 \\
\hline 6 & Rahnella aquatilis strain & $100 \%$ & KP943993 \\
\hline 7 & Erwinia rhapontici strain & $100 \%$ & KP943994 \\
\hline 8 & Rahnella aquatilis strain & $100 \%$ & KP943995 \\
\hline 9 & nd. & - & - \\
\hline 10 & nd & - & - \\
\hline 11 & nd & - & - \\
\hline 12 & Pantoea agglomerans & $100 \%$ & KP943996 \\
\hline
\end{tabular}

${ }^{\mathrm{a}}$ Similarity represents the \% similarity shared with the sequences in the GenBank database. nd: not determined

they were tested for their potential to control FHB in durum wheat in field.

L. plantarum SLG17 exhibited antimicrobial activity against the tested Fusarium strains, and a consistent number of genes responsible for plantaricin production. Beside the role of organic acids which are known to be detrimental for pathogen growth [15], a possible action of plantaricins in the antagonist activity against FHB agents can be suggested. Moreover, results obtained from DGGE profiles of seeds deriving from wheat subjected to both biological treatments (Bio-1 and Bio-2) demonstrated that L. plantarum SLG17 was able to enter the internal tissues of spikelets to become an endophyte. Although no direct evidence (e.g. microscopic examination) was given to show the penetration of the sprayed microorganism, the absence of bands ascribed to L. plantarum in the Ctr profile strengthen the hyphotesis of the endophytic behavior of L. plantarum SLG17. Moreover, no data on Lactobacillus detection on wheat seeds are at present available in the literature, unless in silage fermentation [25]. In addition, B. amyloliquefaciens FLN13 was also able to inhibit in vitro all tested Fusarium strains and possessed the synthetase genes responsible for mycosubtilin, fengycin and surfactin production, which are known to be among the molecules (LPs, polyketides, antibiotics) involved in the antagonistic activity against plant pathogens [13]. In the in vitro antagonistic assay, morphological changes were observed by SEM analyses in the hyphae and macroconidia of F. culmorum Fc1, associated with the presence of an extracellular matrix (Fig. 1). These effects on fungi have already been described by several authors in the presence of different species of Bacillus, as a result of cell wall degradation, increased cell adhesion and lipopeptide excretion [8, 26, 27]. In addition, Gong et al. [28] clearly showed the destructive effect of secondary metabolites (iturin A and plipastatin A) from B. amyloliquefaciens S76-3 in F. graminearum conidia and hyphae. Unfortunately, no evidence on the presence of this strain inside wheat seeds was found in the PCR-DGGE profiles. As also reported by Crane et al. [29], following application of $B$. amyloliquefaciens strain TrigoCor on wheat, most Bacillus cells were present post-application as metabolically dormant spores, thus hindering potential internalization in the host plant. It should also be emphasised that the detection limit for DGGE is in the order of $10^{3} \mathrm{cfu} / \mathrm{ml}$ [30]; as a consequence, microbial groups that are present and active, but whose population is lower than $10^{3} \mathrm{cfu} / \mathrm{ml}$, will not be evidenced.

Beside the clear efficacy of the fungicide treatment, the field trial showed, at GS 87, a significant FHB index reduction (49.6\%) in Bio-1 compared to the untreated subplots. Therefore, the efficacy of a preventive and repetitive treatment with the applied mixture of microorganisms was demonstrated, although this was not associated with a significant increase in kernel yield. On the other hand, the treatment applied twice at flowering (Bio-2) was not effective. This last result is different from what obtained by Schisler et al. [31] who showed a significant DS and DI reduction by using a B. subtilis/ amyloliquefaciens strain at flowering in a field trial. However, as pointed out by the same author and by Crane et al. [29], several factors can contribute to the successful application of FHB antagonists in the field, such as the decline of antagonistic molecule levels on wheat surface within a few days, the deleterious effects of ultraviolet light, available nutrients, host variety and runoff from rainfall and irrigation. Last but not least, the intrinsic properties of the applied microorganisms and the inoculation technology should also be considered.

The identification of excised bands from the DGGE profiles evidenced the detection of different microbial species (P. agglomerans, E. raphontici), commonly isolated from plant tissues [32, 33] and the presence of $F$. culmorum and $F$. graminearum, confirming their endemic presence in wheat kernels. Finally, the PCR-DGGE, targeting lactobacilli, allowed the detection of L. plantarum in Bio-1 and Bio-2 seeds, indicating that the inoculated strain was able to become endophyte. This observation confirms that endophytes may not only derive from the rizosphere, but, as reviewed by Compant et al. [34], they may also originate from other sources, such as the phyllosphere, the anthosphere, or the spermosphere.

\section{Conclusions}

The obtained results suggest a possible use of the two microorganisms in controlling FHB spread throughout all the heading and ripening period, aimed at protecting the spikelets before and during anthesis. Moreover, the 


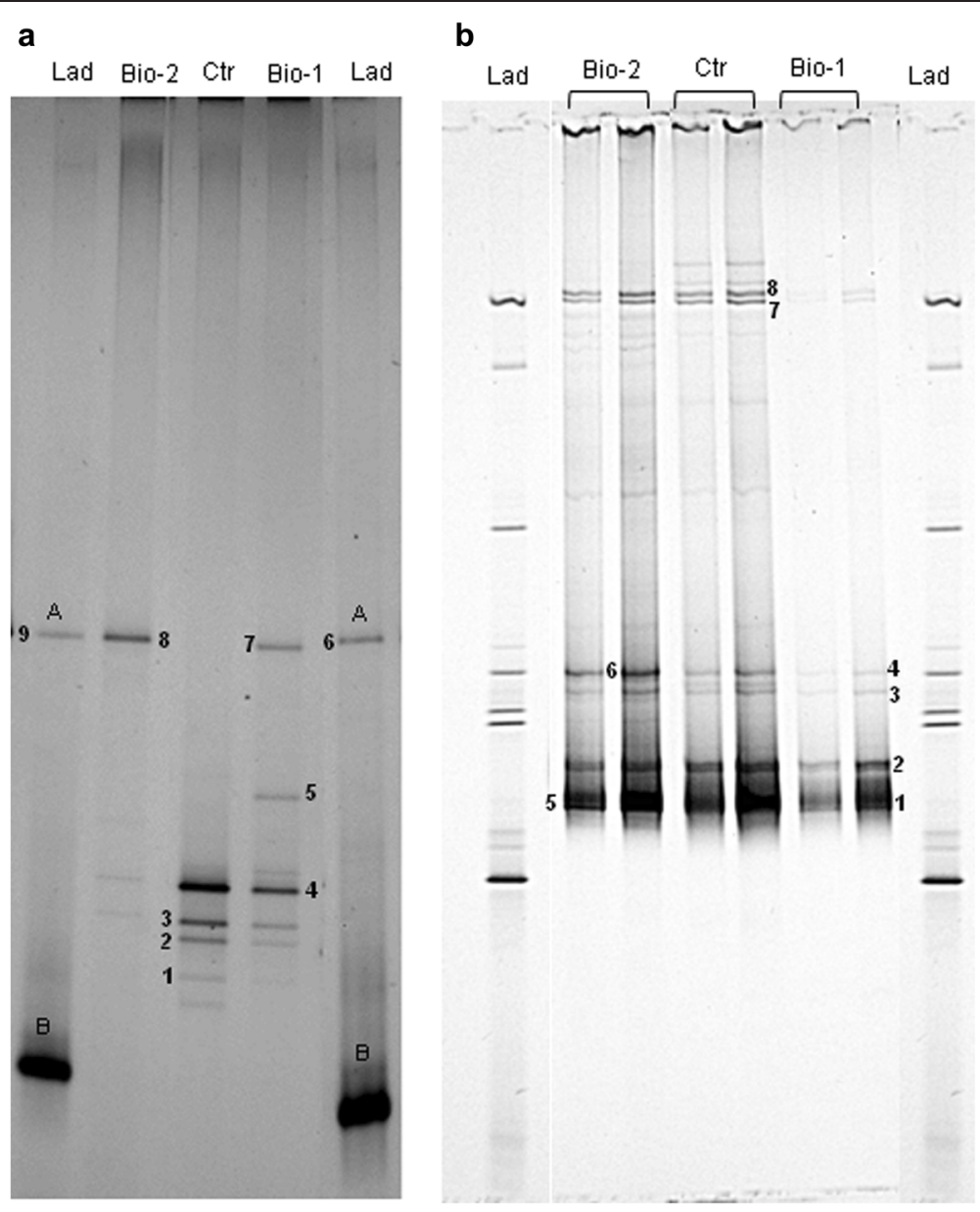

Fig. 3 DGGE patterns of lactobacilli 16S rDNA fragments from wheat seeds (a) and DGGE patterns of partial region of the translation elongation factor1 alpha (EF-1 alpha) gene of Fusarium spp. from wheat seeds (b); Ctr: untreated subplots; Chem: prothioconazole treated subplots; Bio-1: subplots treated with L. plantarum SLG17 and B. amyloliquefaciens FLN13 (weekly treatment-at Zadoks growth stage 50 to 67); Bio-2: subplots treated twice with L. plantarum SLG17 and B. amyloliquefaciens FLN13 at Zadoks growth stage 67 and 70; Lad: Ladder with known microorganism. A: L. plantarum SLG17; B: B. amyloliquefaciens FLN13. Numbers indicate excised and sequenced DGGE bands

endophytic colonization of $L$. plantarum, which is one of the most characterized and used probiotic Lactobacillus species, can help to increase the nutritional properties of wheat and derived products (silages, flour and related bakery products). Further studies are necessary to deeply investigate the interaction with the host plant,

Table $\mathbf{5}$ Lactobacilli sequence alignment with blast

\begin{tabular}{llll}
\hline Band & Closest match & $\%$ similarity $^{\mathrm{a}}$ & Accession number \\
\hline $1-2-3$ & Exiguobacterium sibiricum & $99 \%$ & KP943997 \\
4 & Exiguobacterium sibiricum & $100 \%$ & KP943998 \\
5 & nd & - & - \\
$6-9$ & Lactobacillus plantarum & $100 \%$ & KP943999 \\
$7-8$ & Lactobacillus plantarum & $100 \%$ & KP944000 \\
\hline
\end{tabular}

${ }^{a}$ Similarity represents the \% similarity shared with the sequences in the GenBank database. nd: not determined the metabolite production of both strains and improve the inoculation technology.

\section{Methods}

\section{Microorganisms and culture growth conditions}

This work is based on the use of two microorganisms, $L$. plantarum SLG17, isolated from silages and B. amyloliquefaciens FNL13, isolated from a forest soil, both selected after an in vitro screening aimed at studying the

Table 6 Fusarium sequence alignment with blast

\begin{tabular}{llll}
\hline Band & Closest match & $\%$ similarity $^{\text {a }}$ & Accession number \\
\hline $1-2-5$ & Fusarium culmorum & $100 \%$ & KP944003 \\
$3-4-6$ & Fusarium culmorum & $100 \%$ & KP944002 \\
$7-8$ & Fusarium graminearum strain & $100 \%$ & KP944001
\end{tabular}

${ }^{\mathrm{a}}$ Similarity represents the $\%$ similarity shared with the sequences in the GenBank database 
capability of several Lactobacillus and Bacillus strains of inhibiting the growth of plant pathogenic fungi, including some Fusarium species [35]. These two strains, showing the highest antimicrobial activity, were therefore chosen to perform the current experiments with wheat-isolated strains of F. culmorum and F. graminearum, specifically associated to FHB.

L. plantarum SLG17 was grown on de Man, Rogosa and Sharpe (MRS) broth (BD, Difco, USA) for $24 \mathrm{~h}$ at $37{ }^{\circ} \mathrm{C}$ in anaerobic conditions (1.5\% agar for agar plates); while $B$. amyloliquefaciens FNL13 was grown in Nutrient Broth (NB, BD) for $24 \mathrm{~h}$ at $25-28{ }^{\circ} \mathrm{C}$ under gentle shaking. For long-term storage, microbial strains were stored at $-80^{\circ} \mathrm{C}$.

F. culmorum Fc1, Fc2, Fc3 and F. graminearum Fg1, Fg2 strains, belonging to the main species involved in $\mathrm{FHB}$, were isolated from naturally infected durum wheat kernels (cv Normanno) from fields at the University Farm of Bologna, located in Cadriano (Bologna, Italy) during 2010-2011 and identified by PCR using speciesspecific primers [36] (unpublished results). They were cultivated on Potato Dextrose agar plates (PDA, BD). For long-term storage the fungal strains were stored at $4{ }^{\circ} \mathrm{C}$ in the fungal collection of the Department of Agricultural Sciences, University of Bologna.

\section{Assessment of the antimicrobial activity against Fusarium spp}

Conidia production Fusarium macroconidia inocula were obtained by growing the fungal strains on PDA plates for 7 days (or until sporulation). Then conidia were collected gently scraping the mycelium with a scalpel, filtered in cheese cloth, put into slants with sterile peptone water $(0.2 \% \mathrm{w} / \mathrm{v})$ and the slants were vigorously shaked. Macroconidia concentrations were determined using a haemocytometer, and adjusted to $10^{5}$ macroconidia per $\mathrm{ml}$ of sterile peptone water $(0.2 \% \mathrm{w} / \mathrm{v})$.

Antimicrobial assay The assay was performed according to Magnusson et al. [19]. $50 \mu \mathrm{l}$ of $L$. plantarum and $B$. amyloliquefaciens overnight cultures were spotted on MRS and PDA plates, respectively, and allowed to grow for $24 \mathrm{~h}$ at $37^{\circ} \mathrm{C}$ in anaerobic conditions the former and $25{ }^{\circ} \mathrm{C}$ in aerobiosis the latter. The plates were then overlaid with $10 \mathrm{ml}$ of PD soft agar (0.8\%; Difco Laboratories) containing $10^{5}$ Fusarium spores (macroconidia) per ml. After $48-36 \mathrm{~h}$ of aerobic incubation at $25^{\circ} \mathrm{C}$, the inhibition radius (expressed in $\mathrm{mm}$ ) was measured. Each assay was performed in triplicate and mean $\pm \mathrm{SD}$ was recorded. The antimicrobial assay was also performed between the two antagonistic strains.

\section{SEM analyses}

An agar square $(1 \times 1 \mathrm{~cm})$ plus mycelium was taken from the inhibition area of the dual cultures B. amyloliquefaciens FNL13-F. culmorum Fc1. Sample was immersed in $2.5 \%$ glutaraldehyde for $4 \mathrm{~h}$ at room temperature, rinsed four times with phosphate buffer $(0.1 \mathrm{M} ; \mathrm{pH}$ 7.2), and dehydratated in a graded series of ethanol concentrations (10, 30, 50, 75, 95 and $100 \%$ for 15 min each). It was then dried with a Critical Point Dryer unit (Balzers CPD 020), mounted on aluminium stub with double-sided tape and coated with gold-palladium film using an ion sputtering unit (Balzers MED 010). The sample was observed under a Philips 515 SEM at $7 \mathrm{KV}$ and photographed with Nikon Coolpix 5400.

\section{Detection of genes involved in antagonistic activity}

The presence of genes belonging to $p \ln$ locus $(p \ln \mathrm{G}$, $p \ln \mathrm{E} / \mathrm{F}, p \ln \mathrm{J}, p \ln \mathrm{K}, p \ln \mathrm{N})$ and involved in plantaricin production was investigated according to Doulgeraki et al. [37] on L. plantarum SLG17, following DNA extraction from pure culture. In addition, the presence of four families of lipopeptides synthetase genes (surfactin synthetase, fengycin synthetase, mycosubtilin synthetase and IturinA) were also investigated in Bacillus amyloliquefaciens FLN13. PCR protocols and cloning procedure were performed according to Tapi et al. [38], while iturinA was analyzed according to Alvarez et al. [39] by amplifying the $\mathrm{ItuC}$ open reading frame. Primers used are listed in Table 7.

\section{Field trial}

\section{Experimental trial}

The durum wheat cultivar Normanno, susceptible to FHB agents, was sown in autumn 2012 at the University Farm of Bologna, where durum wheat cultivation is repeated every year. The field was subdivided into small subplots $(1 \mathrm{~m} \times 2.2 \mathrm{~m})$, one subplot represented one replication, and four replications were used for each treatment. Infection of heads by Fusarium spp. was dependent on naturally occurring levels of inoculum and rainfall (20 rainfall events for a total of $5.85 \mathrm{~cm}$ of rain, from flowering until ripening, were observed). The wheat stage of growth was measured using the Zadoks growth stage (GS) [40].

Four different treatments were designed: untreated subplots (Ctr), subplots treated with a prothioconazole-based fungicide (Proline ${ }^{\oplus}$, Bayer Crop Science, Italy), according to the manufacturer instructions (Chem), subplots weekly treated with a suspension of the two microorganisms from heading (GS 50) to the beginning of flowering (GS 67) (Bio-1), subplots treated twice with the microorganisms suspension at GS 67 and at mid-flowering (GS 70) (Bio-2). 
Table 7 List of primers for detection of genes belongs to p/n locus and LPs shyntetase

\begin{tabular}{|c|c|c|c|}
\hline Target gene & Primers & Annealing temperature $\left({ }^{\circ} \mathrm{C}\right)$ & References \\
\hline \multirow[t]{2}{*}{$\overline{p l n E / F}$} & fw: 5'- GGCATAGTTAAAATTCCCCCC-3' & 53.2 & Doulgeraki et al., 2013 [37] \\
\hline & rev: 5'- CAGGTTGCCGCAAAAAAAG-3' & & \\
\hline \multirow[t]{2}{*}{ pln」 } & fw: 5'-TAACGACGGATTGCTCTG-3' & 51 & Doulgeraki et al., 2013 [37] \\
\hline & rev: 5'- AATCAAGAAATTATCACATTAGTC-3' & & \\
\hline \multirow[t]{2}{*}{ plnK } & fw: 5- CTGTAAGCATTGCTAACCAATC & 52.9 & Doulgeraki et al., 2013 [37] \\
\hline & rev: 5- ACTGCTGACGCTGAAAAG & & \\
\hline \multirow[t]{2}{*}{$p \ln G$} & fw: 5- TGCGGTTATCAGTATGTCAAAG & 52.8 & Doulgeraki et al., 2013 [37] \\
\hline & rev: 5-CCTCGAAACAATTTCCCCC & & \\
\hline \multirow[t]{2}{*}{$p \ln \mathrm{N}$} & fw: 5- ATTGCCGGGTTAGGTATCG & 51.9 & Doulgeraki et al., 2013 [37] \\
\hline & rev: 5- CCTAAACCATGCCATGCAC & & \\
\hline \multirow[t]{2}{*}{ Surfactin synthetase } & As1-f CGCGGMTACCGVATYGAGC & $43^{\circ} \mathrm{C}$ & Tapi et al., 2010 [38] \\
\hline & Ts2-r ATBCCTITBTWDGAATGTCCGCC & & \\
\hline \multirow[t]{2}{*}{ Fengycin synthetase } & Af2-f GAATAYMTCGGMCGTMTKGA & $45^{\circ} \mathrm{C}$ & Tapi et al., 2010 [38] \\
\hline & Tf1-r GCTITWADKGAATSBCCGCC & & \\
\hline \multirow[t]{2}{*}{ Mycosubtilins syntetase } & Am1-f CAKCARGTSAAAATYCGMGG & $45^{\circ} \mathrm{C}$ & Tapi et al., 2010 [38] \\
\hline & Tm1-r CCDASATCAAARAADTTATC & & \\
\hline \multirow[t]{2}{*}{ Iturin A synthetase } & ituC-f AAAGGATCCAAGCGTGCCTITACGGGAAA & $56^{\circ} \mathrm{C}$ & Alvarez et al. 2011 [39] \\
\hline & ituC-r AAAAAGCTTAATGACGCCAGCTTTCTCTT & & \\
\hline
\end{tabular}

\section{Production of antagonist inoculum}

L. plantarum SLG17 and B. amyloliquefaciens FNL13 were grown in MRS broth and NB (under shaken), respectively, for $24 \mathrm{~h}$ as previously described. $10 \mathrm{ml}$ of the overnight cultures were used as inoculum in flasks containing $400 \mathrm{ml}$ of broth (MRS and NB) for $48 \mathrm{~h}$ to reach a concentration of approximately $10^{7} \mathrm{cfu} / \mathrm{ml}$. The cultures were then centrifuged (20 min at $12.000 \mathrm{rpm}$ ) and the pellets were combined in $400 \mathrm{ml}$ of sterilized saline solution $(0.8 \% \mathrm{NaCl})$. The microbial inoculum was prepared before each treatment and sprayed immediately on the spikelets on late afternoon (100 ml/subplot).

\section{Assessment of FHB}

Five groups of ten spikes per subplot were chosen and marked with plastic labels for FHB assessment: disease incidence (DI) and disease severity (DS). The disease evaluation was assessed twice at GS 73 and 87. DI was calculated as the percentage of ears that are visibly diseased in relation to the total number assessed (50 spikes/subplot). For DS evaluation, the scale rating of Purahong et al. [41] was applied. This scale represents eight levels of percentage area infected on individual ears: $0 \%$ (no infection), $2 \%, 5 \%, 10 \%, 25 \%, 50 \%, 75 \%$ and $90 \%$ (90\% or more). DS was calculated as the weighted average of percentage area infected on individual ear in relation to the number of infected ears. Mean FHB Index was calculated as the product of DI and DS, divided by 100 [3]. Kernel yield per treatment was evaluated by calculating the average $( \pm S D)$ of the kernel weight obtained from each subplot after harvest. The isolation of F. culmorum and F. gramineraum from 100 wheat grains, harvested from each plot, was performed to verify their presence.

\section{Statistical analysis}

The analysis of variance (ANOVA) was conducted on percentage values subjected to angular transformation for DI, DS and FHB index at both evaluation times. Significant differences among treatments were evaluated using the post hoc Tukey's test with STATGRAPHICS PLUS software (STATPOINT TECHNOLOGIES, INC., Virginia). The level of significance was set at $P \leq 0.05$.

\section{DNA extraction}

Wheat seeds from each treatment were collected two weeks before harvesting, and kept at $4{ }^{\circ} \mathrm{C}$ until further processing. Before DNA extraction, they were surfacesterilized with $70 \%$ ethanol (3 min), treated with $2 \%$ sodium hypochlorite $(\mathrm{NaClO})(5 \mathrm{~min})$, followed by repeated washing with sterile distilled water (3 times for $1 \mathrm{~min})$. An aliquots of the final rinse was plated on Nutrient Agar and Luria-Bertani plates to ensure the surface sterilization efficiency. Later, they were snap frozen in liquid nitrogen and ground by mortar and pestle. Approximately $100 \mathrm{mg}$ of powder was directly used for DNA extraction by applying the DNeasy plant mini kit (Qiagen GmbH, Milano, Italy), according to the manufacturer's instructions. The purity and concentration of extracted DNA were determined by measuring the ratio 
of the absorbance at 260 and $280 \mathrm{~nm}$ (Infinite 200 PRO NanoQuant, Tecan, Mannedorf, Switzerland).

\section{PCR amplification of 16S rDNA sequences and elongation factor1alpha}

Three different PCR amplifications were performed, before DGGE, targeting eubacteria, lactobacilli and Fusarium spp. To avoid the amplification of the chloroplast or mitochondrial DNA, a nested PCR approach was used for the detection of eubacteria, according to Chelius and Triplett [42]. Firstly, a PCR was performed using universal primers $799 f$ (5'-AACMGGATTAGATACCCKG-3') and 1492r (5'-TACGGYTACCTTGTTACGACTT-3'). Following excision of the smaller PCR product $(680 \mathrm{pb})$, a second PCR was then carried out in $30 \mu$ volume, using GC-clamp 968f (5'-CGCCCGGGGCGCGCCCCGGGC GGGGCGGGGGCACGGGGGGAACGCGAAGAACCT TAC-3') and 1348r (5'-CGGTGTGTACAAGGCCCGG GAACG-3'). To deeply analyze possible differences between the treated plots with microorganisms and the Ctr plots, a PCR-DGGE targeting lactobacilli were also performed with primers Lac1 (5'-AGCAGTAGGGAATCTT CCA-3') and Lac2-GC (5' -CGCCCGGGGCGCGCCCCG GGCGGCCCGGGGGCACCGGGGGATTYCACCGCTA CACATG-3') according to Gaggia et al. [17].

In addition, amplification of a partial region of the translation elongation factor1 alpha $(\mathrm{EF}-1 \alpha)$ gene was performed to investigate Fusarium diversity, according to Yergeau et al. [43], using the primer couple Alfie1-GC-f (5'-CGCCCGCCGCGCGCGGCGGGCGGGGCGGGGG CACGGGGGGTCGTCATCGGCCACGTCGACTC-3') and Alfie2-r (5' -CCTTACCGAGCTCRGCGGCTTC-3').

\section{Electrophoretic conditions and identification of bands}

The DGGE analysis was basically performed as first described by Muyzer et al. [44], using a DCode System apparatus (Bio-Rad, Richmond, CA, USA), employing $7 \%$ polyacrylamide gels with a denaturing range of 35-55\% for total eubacteria, 30-55 \% for group-specific lactobacilli and $40-55 \%$ for fungi. Electrophoresis was performed at $65 \mathrm{~V}$ for $16 \mathrm{~h}$ at $60{ }^{\circ} \mathrm{C}$. Gels were stained in a solution of $1 \mathrm{X}$ SYBR-Green (Sigma-Aldrich) in 1X TAE for $20 \mathrm{~min}$ and their images captured in UV transillumination with Gel DocTM 226 XR apparatus (Bio-Rad). Similarities between the DGGE profiles were determined by calculating similarity indices of the densitometric curves of the profiles using Pearson correlation coefficient with the aid of computer software (Gel Compare II, Applied Maths, Keistraat, Belgium). An unweighted pair group method using an arithmetic averages (UPGMA) algorithm was performed.

Well-defined bands in all DGGE experiments were excised from the gel with a sterile scalpel and DNA was eluted by incubating the gel fragments for $16 \mathrm{~h}$ in $50 \mu \mathrm{l}$ of sterile deionised water at $4{ }^{\circ} \mathrm{C}$. Two $\mu$ lof the solutions were then used as template to re-amplify the band fragments using the couple primers $968 \mathrm{f}-\mathrm{GC} / 518 \mathrm{r}$, Lac1-f/ Lac2-GC andAlfie1-GC/Alfie2-r. Then, the positions of the excised bands in DGGE gel were confirmed with repeated DGGE. Bands showing the expected melting position in DGGE gels were amplified with the couple primers, without GC-clamp and the obtained amplicons were purified (Nucleospin gel and PCR clean-up kit; Macherey-Nagel GmbH \& Co. KG, Germany). Finally, purified PCR products were sequenced by a commercial sequencing facility (EurofinsMWG Operon, Ebersberg, Germany). Sequence chromatograms were edited and analysed using the software programs Finch TV version 1.4.0 (Geospiza Inc., Seattle, WA, USA) and identity was then determined by the megablast algorithm in the GenBank database (http://www.ncbi.nlm.nih.gov/BLAST/).

\section{Abbreviations}

FHB: Fusarium head blight; SEM: Scanning electron microscopy; PCRDGGE: Polymerase chain reaction-denaturing gradient gel electrophoresis; GS: Zadoks growth stage; DI: Disease incidence; DS: Disease severity; LPs: lipopeptides; MRS: de Man, Rogosa and Sharpe broth; NB: Nutrient Broth; PDA: Potato Dextrose agar.

\section{Competing interests}

The authors declare they have no competing interests.

\section{Authors' contributions}

$F G, L B$ and DDG designed the study. LB, FG and ND carried out microbiological analyses. AProdi and PN manipulated Fusarium strains. LB, FG and PN carried out the field study. AProdi and APisi performed SEM analyses. FG, LB and DDG wrote the manuscript, which was revised by BB. All Authors read and approved the final manuscript.

\section{Acknowledgements}

This work was done in the framework of the VII FP TRAFOON (Traditional food network to improve the transfer of knowledge for innovation), grant agreement no. 613912. Research on endophytes was performed within the EU COST FA1103 Action: "Endophytes in Biotechnology and Agriculture". ND was the recipient of a fellowship within the JoinEU-SEEIII Action 2 Program.

\section{Author details}

'Department of Agricultural Sciences, University of Bologna, Viale Fanin 44, 40127 Bologna, Italy. ${ }^{2}$ Department of Industrial Chemistry, Faculty of Natural Sciences, Tirana University, Bulevardi Zogu i Parë, Tirana, Albania. ${ }^{3}$ Institute of Earth Systems, Division of Rural Sciences \& Food Systems, University of Malta, Msida, Malta.

Received: 22 July 2015 Accepted: 15 October 2015

Published online: 30 October 2015

\section{References}

1. Bottalico A, Perrone G. Toxigenic Fusarium species and Mycotoxins Associated with Head Blight in Small-Grain Cereals in Europe. Eur J Plant Pathol. 2002;108:611-624

2. Goswami RS, Kistler HC. Heading for disaster: Fusarium graminearum on cereal crops. Mol Plant Pathol. 2004;5:515-25.

3. Xu X. Effects of Environmental Conditions on the Development of Fusarium Ear Blight. Eur J Plant Pathol. 2003;109:683-689

4. Parry DW, Jenkinson P, McLeod L. Fusarium ear blight (scab) in small grain cereals?a review. Plant Pathol. 1995;44:207-38.

5. Pancaldi D, Tonti S, Prodi A, Salomoni D, Pra' MD, Nipoti P, et al. Survey of the main causal agents of fusarium head blight of durum wheat around Bologna, northern Italy. Phytopathologia Mediterranea. 2010;49:258-266. 
6. Shi C, Yan P, Li J, Wu H, Li Q, Guan S. Biocontrol of Fusarium graminearum growth and deoxynivalenol production in wheat kernels with bacterial antagonists. Int J Environ Res Public Health. 2014;11:1094-105.

7. Kabak B, Dobson ADW, Var I. Strategies to prevent mycotoxin contamination of food and animal feed: a review. Crit Rev Food Sci Nutr. 2006;46:593-619.

8. Zhao Y, Selvaraj JN, Xing F, Zhou L, Wang Y, Song H, et al. Antagonistic action of Bacillus subtilis strain SG6 on Fusarium graminearum. PLoS One. 2014;9:e92486

9. He J, Boland GJ, Zhou T. Concurrent selection for microbial suppression of Fusarium graminearum, Fusarium head blight and deoxynivalenol in wheat. J Appl Microbiol. 2009;106:1805-17.

10. Palazzini JM, Ramirez ML, Torres AM, Chulze SN. Potential biocontrol agents for Fusarium head blight and deoxynivalenol production in wheat. Crop Prot. 2007;26:1702-10.

11. Gray EJ, Smith DL. Intracellular and extracellular PGPR: commonalities and distinctions in the plant-bacterium signaling processes. Soil Biol Biochem. 2005;37:395-412

12. Qin S, Xing K, Jiang J-H, Xu L-H, Li W-J. Biodiversity, bioactive natural products and biotechnological potential of plant-associated endophytic actinobacteria. Appl Microbiol Biotechnol. 2011;89:457-73.

13. Raaijmakers JM, De Bruijn I, Nybroe O, Ongena M. Natural functions of lipopeptides from Bacillus and Pseudomonas: more than surfactants and antibiotics. FEMS Microbiol Rev. 2010;34:1037-62.

14. Brader G, Compant S, Mitter B, Trognitz F, Sessitsch A. Metabolic potential of endophytic bacteria. Curr Opin Biotechnol. 2014;27:30-7.

15. Gaggia F, Di Gioia D, Baffoni L, Biavati B. The role of protective and probiotic cultures in food and feed and their impact in food safety. Trends Food Sci Technol. 2011;22:S58-66.

16. De Melo Pereira GV, Magalhães KT, Lorenzetii ER, Souza TP, Schwan RF. A multiphasic approach for the identification of endophytic bacterial in strawberry fruit and their potential for plant growth promotion. Microb Ecol. 2012;63:405-17.

17. Gaggìa F, Baffoni L, Di Gioia D, Accorsi M, Bosi S, Marotti I, et al. Inoculation with microorganisms of Lolium perenne L.: evaluation of plant growth parameters and endophytic colonization of roots. N Biotechnol. 2013;30:695-704.

18. Strom K, Sjogren J, Broberg A, Schnurer J. Lactobacillus plantarum MiLAB 393 Produces the Antifungal Cyclic Dipeptides Cyclo(L-Phe-L-Pro) and Cyclo(L-Phe-trans-4-OH-L-Pro) and 3-Phenyllactic Acid. Appl Environ Microbiol. 2002;68:4322-7.

19. Magnusson J, Ström K, Roos S, Sjögren J, Schnürer J. Broad and complex antifungal activity among environmental isolates of lactic acid bacteria. FEMS Microbiol Lett. 2003;219:129-35.

20. Wang H, Yan Y, Wang J, Zhang H, Qi W. Production and characterization of antifungal compounds produced by Lactobacillus plantarum IMAU10014. PLoS One. 2012;7:e29452

21. Dalié DKD, Deschamps AM, Richard-Forget F. Lactic acid bacteria - Potential for control of mould growth and mycotoxins: A review. Food Control. 2010;21:370-80.

22. Franco TS, Garcia S, Hirooka EY, Ono YS, dos Santos JS. Lactic acid bacteria in the inhibition of Fusarium graminearum and deoxynivalenol detoxification. J Appl Microbiol. 2011;111:739-48.

23. Pérez-García A, Romero D, de Vicente A. Plant protection and growth stimulation by microorganisms: biotechnological applications of Bacilli in agriculture. Curr Opin Biotechnol. 2011;22:187-93.

24. Roselló G, Bonaterra A, Francés J, Montesinos L, Badosa E, Montesinos E. Biological control of fire blight of apple and pear with antagonistic Lactobacillus plantarum. Eur J Plant Pathol. 2013;137:621-33.

25. Cai Y, Benno Y, Ogawa M, Kumai S. Effect of applying lactic acid bacteria isolated from forage crops on fermentation characteristics and aerobic deterioration of silage. J Dairy Sci. 1999:82:520-6.

26. Vitullo D, Di Pietro A, Romano A, Lanzotti V, Lima G. Role of new bacterial surfactins in the antifungal interaction between Bacillus amyloliquefaciens and Fusarium oxysporum. Plant Pathol. 2012;61:689-99.

27. Ongena M, Jacques P. Bacillus lipopeptides: versatile weapons for plant disease biocontrol. Trends Microbiol. 2008;16:115-25.

28. Gong A-D, Li H-P, Yuan Q-S, Song X-S, Yao W, He W-J, et al. Antagonistic mechanism of iturin $A$ and plipastatin $A$ from Bacillus amyloliquefaciens S76-3 from wheat spikes against Fusarium graminearum. PLoS One. 2015;10:e0116871.
29. Crane JM, Gibson DM, Vaughan RH, Bergstrom GC. Iturin levels on wheat spikes linked to biological control of Fusarium head blight by Bacillus amyloliquefaciens. Phytopathology. 2013;103:146-55.

30. Cocolin L, Bisson LF, Mills DA. Direct profiling of the yeast dynamics in wine fermentations. FEMS Microbiol Lett. 2000;189:81-7.

31. Schisler DA, Khan NI, Boehm MJ, Slininger PJ. Greenhouse and Field Evaluation of Biological Control of Fusarium Head Blight on Durum Wheat. Plant Dis. 2002:86:1350-6.

32. Ruppel S, Hecht-Buchholz C, Remus R, Ortmann U, Schmelzer R. Settlement of the diazotrophic, phytoeffective bacterial strain Pantoea agglomerans on and within winter wheat: An investigation using ELISA and transmission electron microscopy. Plant Soil. 1992;145:261-73.

33. Narula N, Remus R, Deubel A, Granse A, Dudeja SS, Behl RK, et al. Comparison of the effectiveness of wheat roots colonization by Azotobacter chroococcum and Pantoea agglomerans using serological techniques. Plant, Soil Environ. 2007;53:167-76.

34. Compant S, Duffy B, Nowak J, Clément C, Barka EA. Use of plant growth-promoting bacteria for biocontrol of plant diseases: principles, mechanisms of action, and future prospects. Appl Environ Microbiol. 2005;71:4951-9.

35. Gaggia F, Dalanaj N, Baffoni L, Prodi A, Alkadri D, Biavati B, et al. Microorganisms as biological agents against pathogenic fungi of agricultural interest. In Schneider C, Leifert C, Feldman F, editors. Endophytes for Plant Protection: The State of the Art. 2013, p. 187. DPG Publisher; ISBN: 9783941261112

36. Nicholson P, Simpson D, Weston G, Rezanoor H, Lees A, Parry D, et al. Detection and quantification ofFusarium culmorumandFusarium graminearumin cereals using PCR assays. Physiol Mol Plant Pathol. 1998;53:17-37.

37. Doulgeraki Al, Paraskevopoulos N, Nychas GJE, Panagou EZ. An in vitro study of Lactobacillus plantarum strains for the presence of plantaricin genes and their potential control of the table olive microbiota. Antonie Van Leeuwenhoek. 2013;103:821-32.

38. Tapi A, Chollet-Imbert M, Scherens B, Jacques P. New approach for the detection of non-ribosomal peptide synthetase genes in Bacillus strains by polymerase chain reaction. Appl Microbiol Biotechnol. 2010;85:1521-31.

39. Alvarez F, Castro M, Príncipe A, Borioli G, Fischer S, Mori G, et al. The plant-associated Bacillus amyloliquefaciens strains MEP2 18 and ARP2 3 capable of producing the cyclic lipopeptides iturin or surfactin and fengycin are effective in biocontrol of sclerotinia stem rot disease. J Appl Microbiol. 2012;112:159-74.

40. Tottman DR. The decimal code for the growth stages of cereals, with illustrations. Ann Appl Biol. 1987;110:441-54.

41. Purahong W, Alkadri D, Nipoti P, Pisi A, Lemmens M, Prodi A. Validation of a modified Petri-dish test to quantify aggressiveness of Fusarium graminearum in durum wheat. Eur J Plant Pathol. 2012;132:381-91.

42. Chelius MK, Triplett EW. The Diversity of Archaea and Bacteria in Association with the Roots of Zea mays L. Microb Ecol. 2001:41:252-63.

43. Yergeau E, Filion M, Vujanovic V, St-Arnaud M. A PCR-denaturing gradient gel electrophoresis approach to assess Fusarium diversity in asparagus. J Microbiol Methods. 2005;60:143-54.

44. Muyzer G, de Waal EC, Uitterlinden AG. Profiling of complex microbial populations by denaturing gradient gel electrophoresis analysis of polymerase chain reaction-amplified genes coding for 165 rRNA. Appl Environ Microbiol. 1993;59:695-700.

\section{Submit your next manuscript to BioMed Central and take full advantage of:}

- Convenient online submission

- Thorough peer review

- No space constraints or color figure charges

- Immediate publication on acceptance

- Inclusion in PubMed, CAS, Scopus and Google Scholar

- Research which is freely available for redistribution 